\title{
Senior Patients Online: Which Functions Should a Good Patient Website Offer?
}

\author{
Nadine Bol ${ }^{1}$, Christin Scholz ${ }^{1}$, Ellen M.A. Smets ${ }^{2}$, Eugène F. Loos ${ }^{1}$, \\ Hanneke C.J.M. de Haes ${ }^{2}$, and Julia C.M. van Weert ${ }^{1}$ \\ ${ }^{1}$ Amsterdam School of Communication Research / ASCoR, University of Amsterdam, \\ Amsterdam, The Netherlands \\ ${ }^{2}$ Department of Medical Psychology, Academic Medical Center / AMC, \\ University of Amsterdam, Amsterdam, The Netherlands \\ n.boleuva.nl
}

\begin{abstract}
This study proposes a theoretical framework for patient website functions and provides empirical input for the framework. A pilot survey among younger (aged 50 -64, $M=55.95, S D=4.48, n=21$ ) and older (aged $65-84$, $M=72.79, S D=6.33, n=14$ ) cancer patients revealed that patients' website preferences vary across type of website functions as well as across age groups. Whereas the majority of patients reported high preference for website functions in general (e.g., information provision), preferences varied across preferred delivery methods of these functions. Furthermore, differences in information preferences indicate a trend of younger patients preferring to search information themselves whereas older patients seem to prefer receiving disease relevant information and practical tips. We provide first evidence for patient preferences regarding specific website functions and thus provide practical implications for website design.
\end{abstract}

Keywords: aging, information preferences, patient website functions, cancerrelated information.

\section{Introduction}

Many Western populations are aging fast [1,2] and consequently show an increase in disease ratings, such as cancer incidences $[3,4]$. At the same time, more cancer-related information is presented through the Internet [5]. On the one hand, it has been found that the Internet fulfills a wide range of information and support needs, and older adults increasingly use the Internet to fulfill those needs [6,7]. On the other hand, website usability is still relatively low among older adults [8]. This is partly due to their inexperience with computer technologies and age-related declines in cognitive functioning, such as reduced working memory and visual impairment $[9,10]$. Nevertheless, there is evidence that older patients might benefit from online information just as much as younger patients as long as websites are designed appropriately $[11,12]$. In addition, Gustafson et al. [13] could not find any differences in overall usage frequency between different age groups. To make full use of the potential benefits that patient 
websites can provide, it is crucial to improve website usability and tailor website design to the rapidly growing older user group [14].

In an attempt to improve online health information and to address patients' needs and preferences, several types of patient websites have been developed and their effects investigated, although not specifically in older populations. Well-documented examples are HowIsYourHealth.org, an online system that registers patient reported outcomes [15], and E-Info Gene, a pre-visit website designed to inform patients prior to breast cancer genetic counseling [16]. These patient websites attempt to address patients' needs and preferences but are often limited to purely informative system functions, such as providing information based on patients' preferences and characteristics $[17,18]$. Other types of website functions, that enable interactivity or patient self-management for instance, have hardly been implemented or investigated. Although specific website design guidelines have been developed to improve patient websites [5], even specifically for older adults [8], these guidelines do not provide practical guidance regarding which functions should be chosen and how these should be presented to users $[19,20]$. Moreover, there is a lack of knowledge about what functions older patients prefer on a patient website. Therefore, this study aims to contribute in two ways. First, we will make a theoretical contribution by proposing a framework in which we provide a detailed categorization of patient website functions. This framework provides a systematic way of looking at website functions that can guide both research and practice. Second, we will provide empirical input from a first application of our framework, providing an overview of younger and older patients' preferences regarding a broad range of website functions.

\section{Toward a Framework of Patient Website Functions}

Website function evaluation is considered to be one of the most important fields of patient website research [23]. However, there is no clear consensus about which functions should be presented on patient websites and how these should be presented. Therefore, we propose a framework that organizes patient website functions based on patients' needs and provides researchers and website designers with concrete examples of how to design and implement such website functions. We used the idea of Kaelber and colleagues [23] to take patients' needs as a starting point for developing the framework. They distinguished between four types of website functions based on patient' needs: information collection, information sharing, information exchange, and self-management. Information collection includes retrieving information from a patient website, such as inquiring about a specific treatment. Information sharing is engaging in one-way sharing of health information with others, and information exchange is engaging in two-way interaction between patients and others. Selfmanagement includes patient behaviors that facilitate management of their own health, such as using mobile medicine tools to track one's medication schedule [24].

As we feel that the presentation of these functions is of major importance in addressing website functions, we propose a website function framework with an additional dimension (see Figure 1). The horizontal axis represents user needs and the 
vertical axis reflects the specific operationalization and delivery methods that have to be considered when choosing and developing concrete website functions. Three steps can be distinguished. First, the needs of website users should be examined to determine the goal of the website, i.e., the website functions. These functions depend upon the needs that a specific website aims to address. In our proposed framework, these functions aim to fulfill the user needs as explained by Kaelber and colleagues [23]. We merged 'information sharing' and 'information exchange' into one category ('information exchange'), because we expect these to have some overlap (e.g., commenting on someone's personal story on a patient website could change sharing into information exchange and a failed attempt to chat with other users could be considered sharing rather than information exchange). Once the needs of website users are known and accompanying functions are determined, researchers and website designers have to focus on more detailed features of how these functions can be operationalized to fulfill user needs (e.g., a search function). The last step in our framework involves identifying concrete delivery methods and design characteristics of the website functions (e.g., whether the information should be presented visually or audiovisually).

\begin{tabular}{l|lll} 
& $\begin{array}{l}\text { Information collec- } \\
\text { tion }\end{array}$ & $\begin{array}{l}\text { Information } \\
\text { Exchange }\end{array}$ & Self-management \\
\hline Functions & $\begin{array}{l}\text { Providing informa- } \\
\text { tion }\end{array}$ & $\begin{array}{l}\text { Enhancing infor- } \\
\text { mation exchange }\end{array}$ & $\begin{array}{l}\text { Promoting self- } \\
\text { management }\end{array}$ \\
$\begin{array}{l}\text { Function operationa- } \\
\text { lization }\end{array}$ & $\begin{array}{l}\text { Type of information } \\
\text { provision }\end{array}$ & $\begin{array}{l}\text { Type of informa- } \\
\text { tion exchange }\end{array}$ & $\begin{array}{l}\text { Type of self- } \\
\text { management }\end{array}$ \\
$\begin{array}{l}\text { Function delivery } \\
\text { methods }\end{array}$ & $\begin{array}{l}\text { Amount of informa- } \\
\text { tion and presentation }\end{array}$
\end{tabular}

Fig. 1. The proposed framework of patient website functions. The horizontal axis represents various types of user needs; the vertical axis represents different steps of how these user needs can be operationalized and delivered. Function delivery methods can be applicable for several website functions which is indicated with arrows in the table.

As we can merely distinguish between limited functions to fulfill user needs, there are countless ways in which these functions can be delivered. For example, a classic website function is to provide information about a specific topic. This one specific function, however, can be expressed in a variety of ways, including varying the amount of information (e.g., tailored to users' content preferences vs. presenting as much information as possible) and the presentation of information (e.g., illustrations and videos). The broadness of the function delivery methods makes it, however, impossible to research all delivery characteristics for all website functions. Fortunately, it is highly likely that preferred delivery methods of one function will repeat themselves in other functions. For instance, preference for audiovisual information is likely to be the same when collecting information as when exchanging information in the online consultation chat room. Therefore, function delivery methods researched in 
this study can be applicable for several website functions. This is indicated in the framework with arrows (see Figure 1).

\section{$3 \quad$ Method}

To provide empirical input for our proposed framework, we surveyed 35 younger (aged $50-64, M=55.95, S D=4.48, n=21$ ) and older (aged $65-84, M=72.79, S D$ $=6.33, n=14$ ) colorectal cancer patients. In assessing age differences, we chose age younger than 65 for the younger age group and age 65 and older as the older age group as these two age groups have been found as worthy of separate analysis in several studies on adulthood development [21] and disease in adulthood [22]. Patients were asked about how they would like information to be presented when using a patient website. Patients were approached through patient association websites (e.g., Federation of Colorectal Cancer website) and related patient websites (e.g., www.stomavereniging.nl). We placed calls for participation on these websites providing a link to the online questionnaire. Additionally, colorectal patients were approached in the waiting room of the Academic Medical Center (AMC) in Amsterdam and were asked to provide their e-mail addresses to receive the online questionnaire and complete it at home.

Patients were asked to fill out an online questionnaire about their preferences regarding patient website functions. Applying our framework to determine which functions should be on a patient website and how they should be presented, we developed thirty items that covered commonly used website functions and asked patients what preferences they had regarding function operationalization and delivery. Items about information collection included questions such as "I would like to have a good search function to search for relevant information" and "I would like to have access to my personal health record to see test results". Information exchange involved questions such as "I would share own experiences about my disease and treatment with other patients" and "I would like the possibility of online consultations with my physician". Finally, functions on self-management were translated into questions such as "I would fill out a short question prompt sheet to indicate questions I want to ask during the next consultation with my physician" and "I would like to have the option of keeping a personal medical dairy". All 30 items were measured on a 7-point Likert scale, ranging from 1 'totally disagree' to 7 'totally agree'.

\section{$4 \quad$ Results}

The primary findings from our pilot survey are summarized below. We first show how the patient website functions can be organized within our framework. Second, we present our findings regarding the differences in patient website function preferences between younger and older patients. 


\subsection{Empirical Input for Our Framework of Patient Website Functions}

At the level of function operationalization, we found for information collection that patients agreed that having suggestions for relevant information from a physician or nurse would be helpful $(M=6.11, S D=1.18)$. Information exchange functions showed some variation in patient responses. For instance, patients reported a high preference for asking questions to a physician online $(M=6.26, S D=1.29)$, however, they showed a lower need for sharing experiences with other patients $(M=4.06$, $S D=2.16$ ). For self-management, patients found it important to receive practical information and advice about how to deal with their disease in daily life $(M=6.11$, $S D=1.18$ ). However, there was a relatively lower preference for keeping a personal medical dairy on a patient website $(M=4.57, S D=2.03)$.

At the level of function delivery methods, we observed the least variation in the amount of information preferred and the most variation in presentation preferences. Regarding the amount of information, most patients wanted to receive as much information as possible about their disease and treatment $(M=6.37, S D=1.11)$, whereas receiving information that is not directly relevant was preferred less $(M=3.54$, $S D=1.96)$. Patients showed a lot of variation in their information presentation preferences. For example, patients rated having videos on the patient website in which a physician explains complex treatments quite high $(M=5.63, S D=1.70)$, whereas videos in which a patient explains complex treatments were rated relatively lower $(M$ $=3.91, S D=1.99$ ). Below is an example of how to organize patient website functions in terms of operationalization and delivery methods according to our proposed framework of patient website functions (Figure 2). The appendix gives a full overview and organization of all patient website functions and their means $(S D)$.

\begin{tabular}{|c|c|c|c|}
\hline & \begin{tabular}{|l} 
Information collec- \\
tion
\end{tabular} & $\begin{array}{l}\text { Information } \\
\text { Exchange }\end{array}$ & Self-management \\
\hline$\overline{\text { Functions }}$ & Providing information & $\begin{array}{l}\text { Enhancing informa- } \\
\text { tion exchange }\end{array}$ & $\begin{array}{l}\text { Promoting self- } \\
\text { management }\end{array}$ \\
\hline $\begin{array}{l}\text { Function operationali- } \\
\text { zation }\end{array}$ & $\begin{array}{l}\text { Suggestions; } \\
\text { search function; } \\
\text { access to PHR; FAQ; } \\
\text { topic list }\end{array}$ & $\begin{array}{l}\text { Ask questions to phy- } \\
\text { sician; make appoint- } \\
\text { ment; share \& read } \\
\text { experiences; help } \\
\text { others; online consul- } \\
\text { tation; suggestions }\end{array}$ & $\begin{array}{l}\text { Practical support; } \\
\text { QPS; medicine sche- } \\
\text { dule; save } \\
\text { information; } \\
\text { medical dairy }\end{array}$ \\
\hline $\begin{array}{l}\text { Function delivery } \\
\text { methods }\end{array}$ & $\begin{array}{l}\text { Amount of informa- } \\
\text { tion; facts; illustra- } \\
\text { tions; videos }\end{array}$ & & \\
\hline
\end{tabular}

Fig. 2. An example how to organize patient website function according to the framework. Note that this is an example of how the framework can be used, not a fixed classification of patient website functions. Abbreviations: PHR: personal health record; FAQ: frequently asked questions; QPS: question prompt sheet. 


\subsection{Patient Website Function Preferences in Younger and Older Patients}

Patients generally reported high preferences for all patient website functions (see appendix). Yet, we found some differences in these preferences between younger and older patients. Younger patients reported on average higher scores on the patient website functions than older patients (resp. $M=5.38, S D=0.80$ and $M=4.87, S D=1.25$, $p=.058$ ), indicating that younger patients have a stronger preference toward patient website functions than older patients. The top- 5 patient website function preferences for both younger and older patients (see Table 1 and 2 respectively) showed some overlap and some differences between younger and older patients' function preferences. For instance, both younger and older patients' top-5 included similar information collection preferences. Both age groups preferred to receive as much information as possible about disease and treatment and would like to receive suggestions from health care providers about relevant information. With regard to information exchange functions, both groups would like the option of asking questions to the physician online. However, younger patients ranked this function higher ( $2^{\text {nd }}$ place) than older patients $\left(5^{\text {th }}\right.$ place $)$.

Differences between younger and older patients are also shown in Table 1 and 2. Whereas younger patients reported higher preference for having a good search function and a frequently asked questions section to find relevant information themselves, older patients rather preferred information that is specifically relevant to their own disease as opposed to more general information. Furthermore, older patients highly preferred to get practical information and advice about how to handle disease in daily life through a patient website.

To conclude, younger and older patients are similar with respect to some information collection preferences, such as wanting to receive as much information as possible about their own disease and treatment. On the other hand, differences in information preferences indicate a trend of younger patients preferring to search information themselves whereas older patients seem to prefer receiving disease relevant information and practical tips through a patient website.

Table 1. Top-5 patient website function preferences in younger patients $(n=21)$

\begin{tabular}{lcc}
\hline & \multicolumn{2}{c}{$\begin{array}{c}\text { Younger patients } \\
(50-64 \text { yrs. })\end{array}$} \\
Website function & $M$ & $S D$ \\
\hline Ask questions to physician online (E) & 6.57 & 0.75 \\
As much information as possible about disease and treatment (C) & 6.57 & 0.81 \\
Search function to search for relevant information (C) & 6.38 & 1.02 \\
Suggestions from physician/nurse about relevant information (C) & 6.29 & 0.90 \\
Frequently asked questions (FAQ) (C) & 6.19 & 1.12 \\
\hline
\end{tabular}

Abbreviations: C: Information collection; E: Information exchange 
Table 2. Top-5 patient website function preferences in older patients $(n=14)$

\begin{tabular}{llc}
\hline & \multicolumn{2}{c}{$\begin{array}{c}\text { Older patients } \\
(65-84 \text { yrs. })\end{array}$} \\
Website function & $M$ & $S D$ \\
\hline Practical information and advice how to handle disease in daily life & 6.07 & 1.33 \\
(SM) & & \\
As much information as possible about disease and treatment (C) & 6.07 & 1.44 \\
Information that is relevant (C) & 5.86 & 1.35 \\
Suggestions from physician/nurse about relevant information (C) & 5.86 & 1.51 \\
Ask questions to physician online (E) & 5.79 & 1.76 \\
\hline
\end{tabular}

Abbreviations: C: Information collection; E: Information exchange; SM: Self-management

\section{Conclusion and Discussion}

This study provides theoretical and empirical contributions suggesting how patient website functions can be researched and implemented in different age groups. We first proposed a theoretical framework in which we provided a detailed categorization and a systematic way of analyzing and operationalizing patient preferences using patient websites. Second, we applied this framework in a pilot by surveying 35 cancer patients about their preferences regarding a broad set of website functions.

Our results revealed interesting patterns of patient website function preferences. For instance, the majority of patients agreed upon the importance of wanting as much information as possible and receiving information and advice about how to handle their disease in daily life. However, mostly there was considerable variation in preferences regarding the operationalization of website functions. Most patients reported wanting to receive information and suggestions from authority figures, such as physicians and nurses or wanting a good search functions to look up information themselves. Patients expressed less preference for receiving suggestions from other patients about disease and treatment. At the level of function delivery methods, we found a similar pattern. Again, patients reported to prefer information presented by authority figures, such as videos in which physicians explain complex treatments, rather than information presented by peer figures, such as videos in which other patients explained treatments or shared their experience with disease and treatment. These results highlight the importance of various operationalizations and delivery methods of function presentation as patients report differences in how they would like to fulfill their needs in terms of information collection, information exchange, and self-management.

In addition to variation across website function preferences, we also found variation between younger and older patients. Younger patients reported in general higher scores on the patient website function preferences than older ones. Differences in information preferences indicate a trend of younger patients preferring to search information themselves whereas older patients seem to prefer receiving disease relevant information and practical tips through a patient website. The socio-emotional selectivity theory [25] explains that younger adults hold more knowledge acquisition goals 
which shift toward more emotional goals as they age. The salience of knowledge acquisition goals in the younger age group as compared to the older age group is displayed in these results quite well.

Our results extend and contribute to the existing knowledge on patient website functions and how these can be operationalized and delivered to both younger and older cancer patients. It should be noted that the framework we provided neither contains a complete, nor an exhausting list of patient website functions and ways to operationalize and deliver them. More research should be done to explore other relevant website functions and how patients would evaluate these. Also, the opinion of health care providers should be included in examining patient website functions as health care providers are seen as an important source of health information and essential promoters of patient websites [26]. Without the support of the health care staff, the success of a patient website would be highly unlikely.

\section{References}

1. Garssen, J.: Demografie Van De Vergrijzing (Demography of Aging), http: / / www . cbs.nl/NR/rdonlyres / D7D8F678-F22B-445F-8A6FA635D376A344/0/2011demografievandevergrijzingart.pdf

2. World Health Organization: 10 Facts on Ageing and the Life Course, http://www. who.int/features/factfiles/ageing/en/index.html

3. Dutch Cancer Society: Kanker in Nederland Tot 2020: Trends En Prognoses (Cancer in the Netherlands Up to 2020: Trends and Prognoses) (2011),

http: / / repository.kwfkankerbestrijding.nl/PublishingImages / KWF $\% 2$ Kanker\%2 0 in\%2 0Nederland\%202020_zonder\%20 cover.pdf

4. American Cancer Society: Cancer Facts and Figures (2012), http: / /www. cancer. org/acs / groups / content/epidemiologysurveil ance/documents / document/acspc-031941.pdf

5. Morrell, R.W.: Older Adults, Health Information, and the World Wide Web. Lawrence Erlbaum Associates, Inc., Mahwah (2002)

6. Statistics Netherlands: Ouderen Maken Een Inhaalslag Op Het Internet (Elderly Catching Up on the Internet), http: / www . cbs.nl/nl-nl/menu/themas/vrije-tijdcultuur/publicaties/artikelen/archief/2011/2011-3537-wm.htm

7. Ziebland, S.: The Importance of Being Expert: The Quest for Cancer Information on the Internet. Soc. Sci. Med. 59, 1783-1793 (2004)

8. Pernice, K., Nielsen, J.: Web Usability for Senior Citizens: Design Guidelines Based on Usability Studies with People Age 65 and Older. Nielsen Norman Group, Fremont (2002)

9. Parrott, R., Raup Krieger, J., Silk, K., et al.: Aging Adults and Online Cancer Information: Promises and Pitfalls in an Era of Genomic Health Care. In: Sparks, L., O’Hair, H., Kreps, G. (eds.) Cancer, Communication and Aging, pp. 47-66. Hampton Press, Inc., New York (2008)

10. Becker, S.A.: A Study of Web Usability for Older Adults Seeking Online Health Resources. ACM Transactions on Computer-Human Interaction (TOCHI) 11, 387-406 (2004)

11. Alemagno, S.A., Niles, S.A., Treiber, E.A.: Using Computers to Reduce Medication Misuse of Community-Based Seniors: Results of a Pilot Intervention Program. Geriatric Nursing 25, 281-285 (2004) 
12. Neafsey, P.J., Strickler, Z., Shellman, J., et al.: An Interactive Technology Approach to Educate Older Adults about Drug Interactions Arising from Over-the-Counter SelfMedication Practices. Public Health Nursing 19, 255-262 (2002)

13. Gustafson, D.H., Hawkins, R.P., Boberg, E.W., et al.: CHESS: 10 Years of Research and Development in Consumer Health Informatics for Broad Populations, Including the Underserved. Int. J. Med. Inf. 65, 169-177 (2002)

14. Money, A.G., Lines, L., Fernando, S., Elliman, A.D.: e-Government Online Forms: Design Guidelines for Older Adults in Europe. Universal Access in the Information Society 10, $1-16(2011)$

15. Jones, J.B., Snyder, C.F., Wu, A.W.: Issues in the Design of Internet-Based Systems for Collecting Patient-Reported Outcomes. Quality of Life Research 16, 1407-1417 (2007)

16. Albada, A., van Dulmen, S., Otten, R., et al.: Development of E-Info Gene ${ }^{\text {ca. }}$ A Website Providing Computer-Tailored Information and Question Prompt Prior to Breast Cancer Genetic Counseling. Journal of Genetic Counseling 18, 326-338 (2009)

17. Albada, A., Ausems, M.G.E.M., Otten, R., et al.: Use and Evaluation of an Individually Tailored Website for Counselees Prior to Breast Cancer Genetic Counseling. Journal of Cancer Education 26, 670-681 (2011)

18. Clayman, M.L., Boberg, E.W., Makoul, G.: The use of Patient and Provider Perspectives to Develop a Patient-Oriented Website for Women Diagnosed with Breast Cancer. Patient Educ. Couns. 72, 429-435 (2008)

19. Lafky, D.B., Horan, T.A.: Prospective Personal Health Record Use among Different User Groups: Results of a Multi-Wave Study. In: 41st Hawaii International Conference on System Sciences, pp. 233-241. IEEE Press, New York (2008)

20. Tang, P.C., Ash, J.S., Bates, D.W., et al.: Personal Health Records: Definitions, Benefits, and Strategies for Overcoming Barriers to Adoption. Journal of the American Medical Informatics Association 13, 121-126 (2006)

21. Staudinger, U.M., Bluck, S.: A view on midlife development from life-span theory. In: Lachman, M.E. (ed.) Handbook of Midlife Development, pp. 3-39. John Wiley \& Sons, New York (2001)

22. Silliman, R.A., Troyan, S.L., Guadagnoli, E., Kaplan, S.H., Greenfield, S.: The impact of age, marital status, and physician-patient interactions on the care of older women with breast carcinoma. Cancer 80, 1326-1334 (1997)

23. Kaelber, D.C., Jha, A.K., Johnston, D., et al.: A Research Agenda for Personal Health Records (PHRs). Journal of the American Medical Informatics Association 15, 729-736 (2008)

24. López-Nores, M., Blanco-Fernández, Y., Pazos-Arias, J.J., et al.: The iCabiNET System: Harnessing Electronic Health Record Standards from Domestic and Mobile Devices to Support Better Medication Adherence. Computer Standards \& Interfaces 34, 109-116 (2012)

25. Carstensen, L.L., Fung, H.H., Charles, S.T.: Socioemotional Selectivity Theory and the Regulation of Emotion in the Second Half of Life. Motiv. Emotion 27, 103-123 (2003)

26. Ferguson, T.: Online Patient-Helpers and Physicians Working Together: A New Partnership for High Quality Health Care. BMJ 321, 1129-1132 (2000) 


\section{Appendix: Overview of all Patient Website Functions}

\begin{tabular}{|c|c|c|}
\hline Website function & $M$ & $S D$ \\
\hline \multicolumn{3}{|l|}{ Information collection } \\
\hline \multicolumn{3}{|l|}{ Function operationalization } \\
\hline Suggestions from physician/nurse about relevant information & 6.11 & 1.18 \\
\hline Search function to search for relevant information & 6.11 & 1.35 \\
\hline Access to personal health record (PHR) to see test results & 5.89 & 1.81 \\
\hline Frequently asked questions (FAQ) & 5.71 & 1.66 \\
\hline Receive relevant information based on personal health record (PHR) & 5.63 & 1.93 \\
\hline Topic list that would help to find information on the website & 5.06 & 1.92 \\
\hline Suggestions from other patients about what would be relevant information & 4.40 & 2.00 \\
\hline Suggestions linked to previous search & 4.03 & 2.11 \\
\hline \multicolumn{3}{|l|}{ Function delivery methods } \\
\hline \multicolumn{3}{|l|}{ Amount of information } \\
\hline As much information as possible about disease and treatment & 6.37 & 1.11 \\
\hline Only information that is relevant & 5.63 & 1.54 \\
\hline Information that is not directly relevant & 3.54 & 1.96 \\
\hline \multicolumn{3}{|l|}{ Presentation } \\
\hline Videos in which physician explains complex treatments & 5.63 & 1.70 \\
\hline Illustrations of complex treatments and complications & 5.46 & 1.77 \\
\hline (scientific) Facts and statistics & 5.43 & 1.77 \\
\hline Illustrations to make website more attractive & 5.14 & 1.70 \\
\hline Videos in which patients share their experience with disease and treatment & 4.57 & 1.95 \\
\hline Videos in which patient explains complex treatments & 3.91 & 1.99 \\
\hline \multicolumn{3}{|l|}{ Information exchange } \\
\hline \multicolumn{3}{|l|}{ Function operationalization } \\
\hline Ask questions to physician online & 6.26 & 1.29 \\
\hline Make appointment with hospital online & 5.74 & 1.58 \\
\hline Online consultation with physician & 5.34 & 1.85 \\
\hline Help other patients & 5.06 & 1.85 \\
\hline Read other patients' experiences with disease and treatment & 4.91 & 2.02 \\
\hline Suggestions and advice from other patients & 4.17 & 2.02 \\
\hline Share own experiences about disease and treatment with other patients & 4.06 & 2.16 \\
\hline \multicolumn{3}{|l|}{ Information self-management } \\
\hline \multicolumn{3}{|l|}{ Function operationalization } \\
\hline Practical information and advice how to handle disease in daily life & 6.11 & 1.18 \\
\hline Option to save information to be retrieved later & 5.66 & 1.71 \\
\hline Fill out question prompt sheet (QPS) to indicate questions for consultation & 5.40 & 1.75 \\
\hline Fill out a questionnaire to receive tailored information & 5.34 & 1.83 \\
\hline Maintain a medicine schedule & 5.14 & 1.88 \\
\hline Keep a personal medical dairy & 4.57 & 2.03 \\
\hline
\end{tabular}

Note. Function delivery methods might be translated to other types of website functions as well. Patient website functions are presented from most preferred to least preferred within the categories of our framework 